
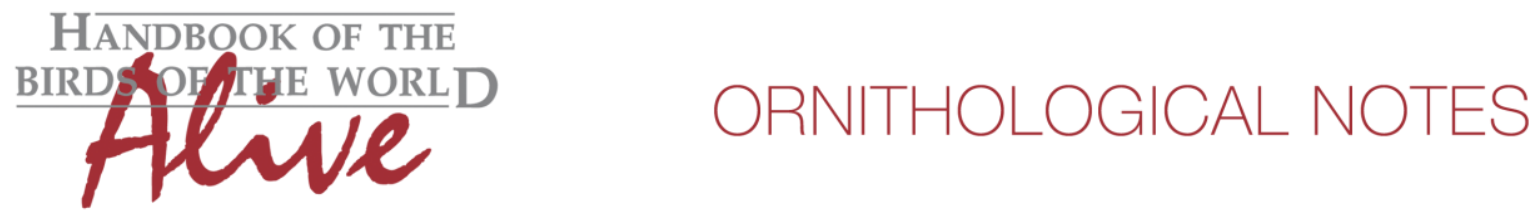

\title{
Notes on the vocalizations of White-crowned Forktail (Enicurus leschenaulti)
}

Peter Boesman

In the following we briefly analyze and compare voice of the different races of Whitecrowned Forktail (Enicurus leschenaulti). We also try to quantify the extent of any vocal differences using the criteria proposed by Tobias et al. (2010), as a support for taxonomic review. We have made use of sound recordings available on-line from Xeno Canto (XC).

Our main interest is to compare race borneensis of the Bornean highlands with other races, as a genetic analysis suggests a high divergence from lowland populations on the island (Moyle et al. 2005).

There are a few recordings available of borneensis, all of a high-pitched slightly descending single whistle, starting at c. $6-6.5 \mathrm{kHz}$ and ending at c. $5.5 \mathrm{kHz}$, with a note length of c. $0.5-$ 0.6s:
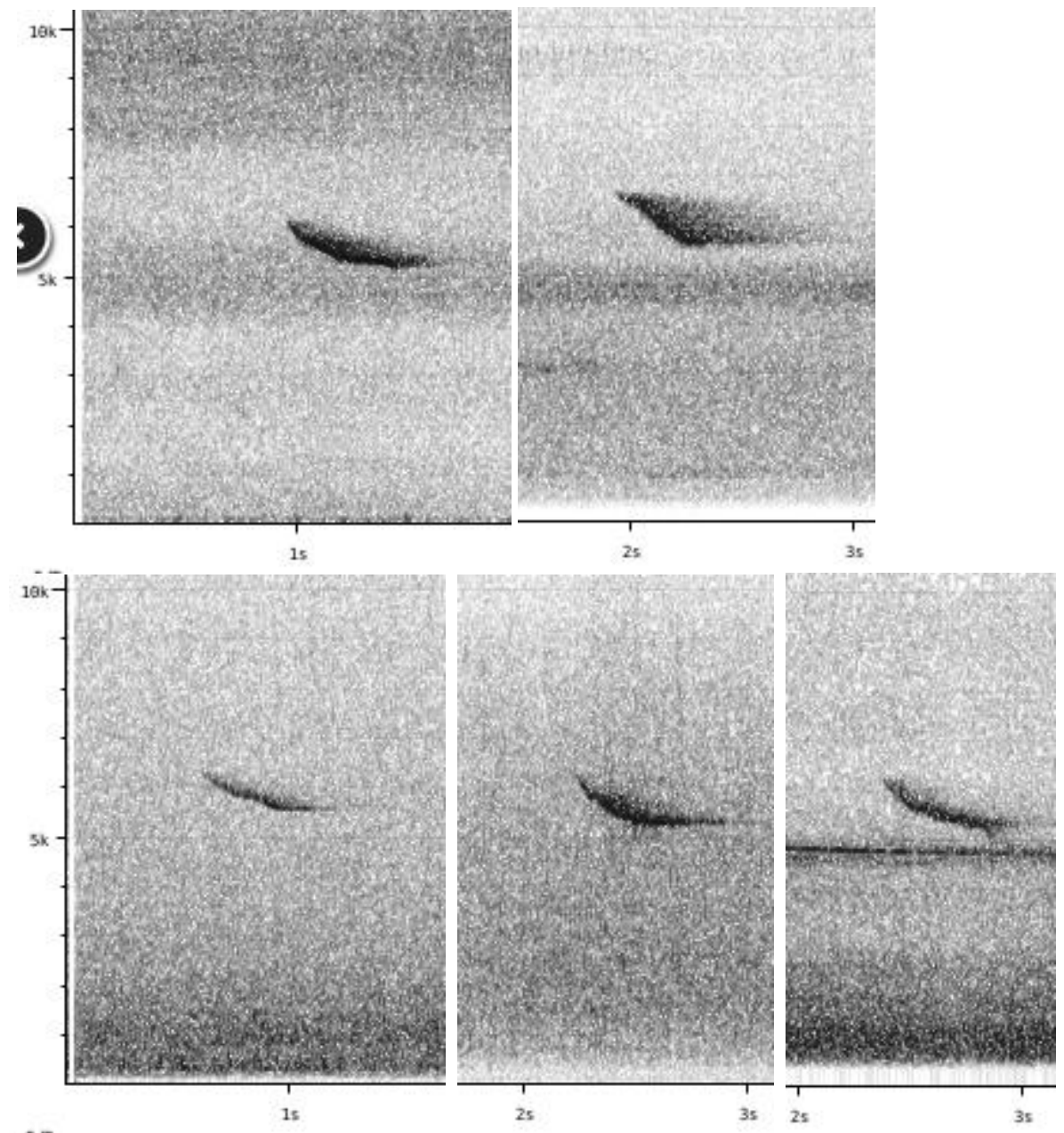

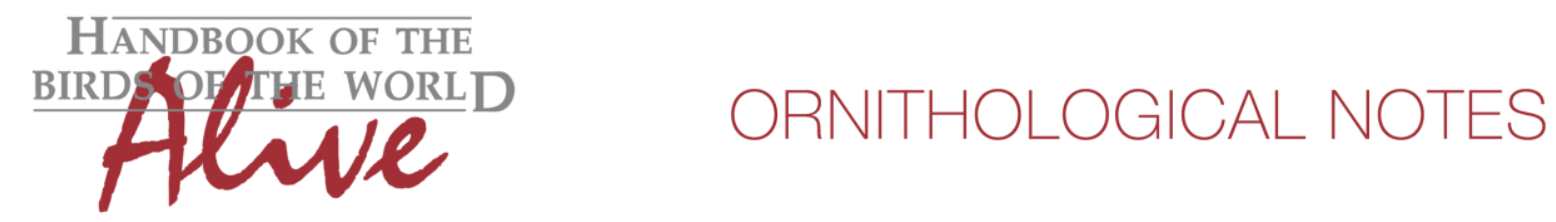

To be compared with voice of other races:

Thailand

China
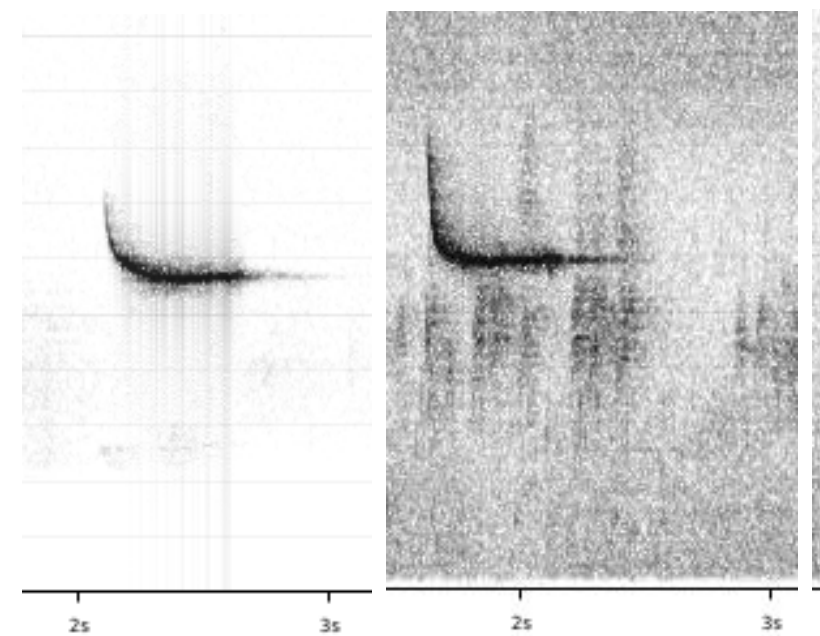

Malaysia (Borneo)

Myanmar
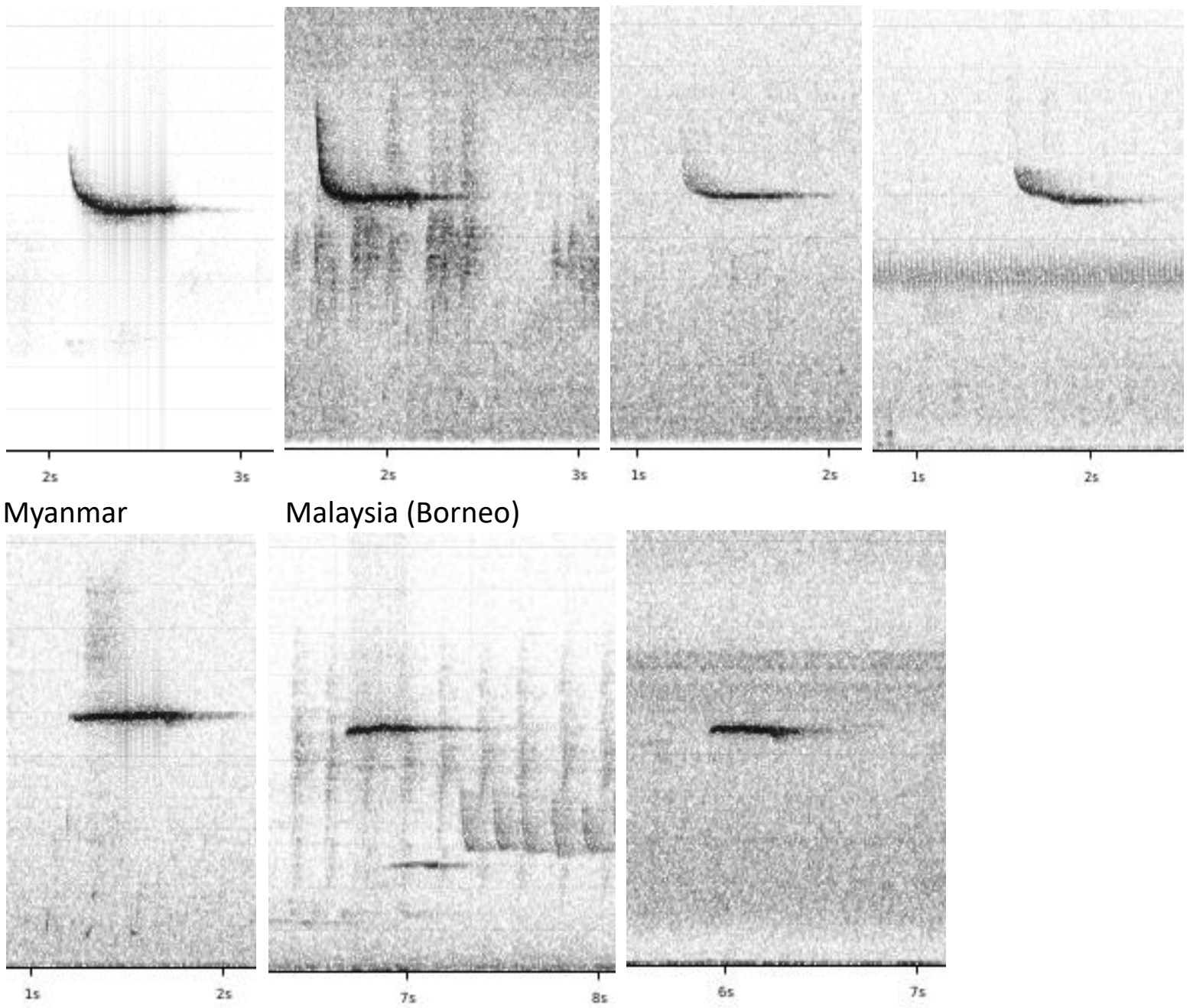

It would seem that there is a slight difference between borneensis and other races:

Whistle of borneensis decreases gradually in pitch. All other races show a sharp decrease at first (or none at all) while the second half of the whistle is at flat pitch. There is a slight overlap, but most whistles can be identified (score 1-2).

In borneensis, frequency decreases to c. $5.5 \mathrm{kHz}$. In other races min. freq. on average slightly higher (score 0-1). These differences are quite subtle, but may nevertheless be of significance as this simple call note seems to be the most common vocalization. True song is heard much less, and there are only very few recordings available, and none of race borneensis. When these become available, comparison would obviously reveal interesting additional information. By applying Tobias criteria on this homologous call, we get a total vocal score of about 2 .

This note was finalized on 10th May 2016, using sound recordings available on-line at that moment. We would like to thank in particular the sound recordists who placed their recordings for this species on XC: Tjalle Boorsma, Gao Chang, Niels Poul Dreyer, David Edwards, David Farrow, Ross Gallardy, Greg Irving, Frank Lambert, Simon Mitchell, Mike Nelson, Niall Perrins and John van der Woude. 


\section{References}

Moyle, R.G., Schilthuizen, M., Rahman, M.A. and Sheldon, F.H. (2005). Molecular phylogenetic analysis of the white-crowned forktail Enicurus leschenaulti in Borneo. J. Avian. Biol. 36(2): 96-101.

Tobias, J.A., Seddon, N., Spottiswoode, C.N., Pilgrim, J.D., Fishpool, L.D.C. \& Collar, N.J. (2010). Quantitative criteria for species delimitation. Ibis 152(4): 724-746.

\section{Recommended citation}

Boesman, P. (2016). Notes on the vocalizations of White-crowned Forktail (Enicurus leschenaulti). HBW Alive Ornithological Note 326. In: Handbook of the Birds of the World Alive. Lynx Edicions, Barcelona. (retrieved from http://www.hbw.com/node/1252621 on 21 October 2016). 